Bull. Mater. Sci., Vol. 22, No. 5, August 1999, pp. 905-915. I Indian Academy of Sciences.

\title{
Chitin and chitosan fibres: A review
}

\author{
M N V RAVI KUMAR \\ Department of Chemistry, University of Roorkee, Roorkee 247 667, India
}

\begin{abstract}
Chitin is the most abundant natural amino polysaccharide and estimated to be produced annually almost as, much as cellulose. It has become of great interest not only as an underutilized resource, but also as a new functional material of high potential in various fields and the recent progress in chitin chemistry is quite noteworthy. The purpose of this review is to take a closer look at fibres made of chitin and its derivatives. Based on the current research and existing products, some new and futuristic approaches, in the development of novel fibres and their applications have been thoroughly discussed.
\end{abstract}

Keywords. Chitin; chitosan; fibres.

\section{Introduction}

Chitin is a high-molecular weight linear polymer of $\mathrm{N}$ acetyl-D-glucosamine (N-acetyl-2-amino-2-deoxy-D-glucopyranose) units linked by $\beta-D(1 \rightarrow 4)$ bonds. It is a highly insoluble material resembling cellulose in its solubility and low chemical reactivity. It may be regarded as cellulose with the hydroxyl at position $\mathrm{C}-2$ replaced by an acetamido group. Like cellulose, it naturally functions as a structural polysaccharide. It is most abundant in crustaceans, insects and fungi. Chitin is a white, hard inelastic, nitrogenous polysaccharide and the major source of surface pollution in coastal areas (Madhavan 1992). Chitosan is the $\mathrm{N}$-deacetylated derivative of chitin, though this $\mathbf{N}$-deacetylation is almost never complete. A sharp nomenclature border has not been defined between chitin and chitosan based on the degree of N-deacetylation (Muzzarelli 1973; Zikakis 1984). Structures of cellulose, chitin and chitosan are shown in figure 1.

Chitin and chitosan are of commercial interest due to their high percent nitrogen $(6.89 \%)$ compared to synthetically substituted cellulose $(1.25 \%)$. This makes chitin a useful chelating agent (Muzzarelli 1973). Many reviews and articles have been published covering the applications of chitin and its derivatives in the areas of pharmaceutical and biomedical applications, paper production, textile finishes, photographic products, cements, heavy metal chelating agents, cosmetics, effluent treatment methods and in engineering applications, for example, solid state batteries (Pariser and Lombadi 1980; Chandy and Sharma 1990; Rathke and Hudson 1994; Yao et al 1995; Salmon and Hudson 1997; Ravi Kumar et al 1998a, b, 1999a, b).
Chitin is a unique material for versatile applications. However, no comprehensive review has yet been published, emphasizing recent progress in fibre research using chitin and chitosan. These fibres could be useful commercially for membranes, hallow fibres, fibres and films to serve as the media for the production of such end products as non wovens (Yamaguchi et al 1987; Kifune et al 1988; Kanayama and Endo 1991; Gessner 1992), paper (Kobayashi et al 1982; Nishiyama et al 1983; Taguchi and Sato 1989; Gorovoi et al 1990; Mori and Yamazaki 1991), medical gauzes, sutures and wound dressings (Kifune et al 1987; Muzzarelli 1993).

\subsection{Processing of chitin and chitosan}

Chitin is easily obtained from crab or shrimp shells and fungal mycelia. In the first case, chitin production is associated with food industries such as shrimp canning. In the second case, the production of chitosan-glucan complexes is associated with fermentation processes, similar to those for the production of citric acid from Aspergillus niger, Mucor rouxii, and streptomyces, which involves alkali treatment yielding chitosan-glucan complexes. The alkali removes the protein and deacetylates chitin simultaneously. Depending on the alkali concentration some alkali soluble glycans are also removed (Muzzarelli et al 1980). The processing of crustacean shells mainly involves the removal of proteins and the dissolution of calcium carbonate that is present in crab shells in high concentrations. The resulting chitin is deacetylated in $40 \%$ sodium hydroxide at $120^{\circ} \mathrm{C}$ for $1-3 \mathrm{~h}$. This treatment produces $70 \%$ deacetylated chitosan (scheme 1).

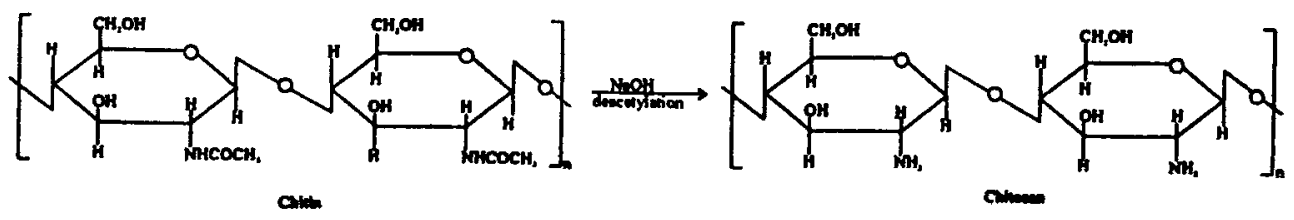

Scheme 1. 


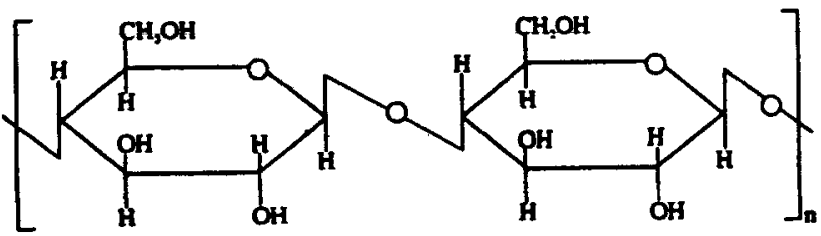

Cellulowe

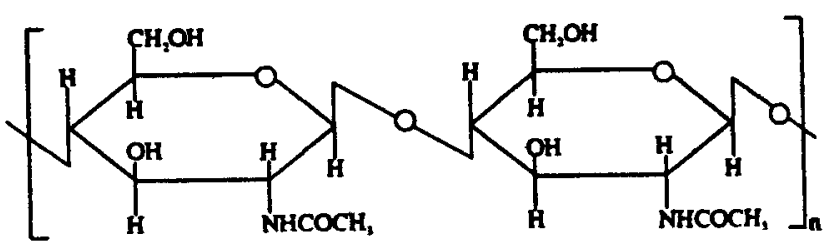

Chitin

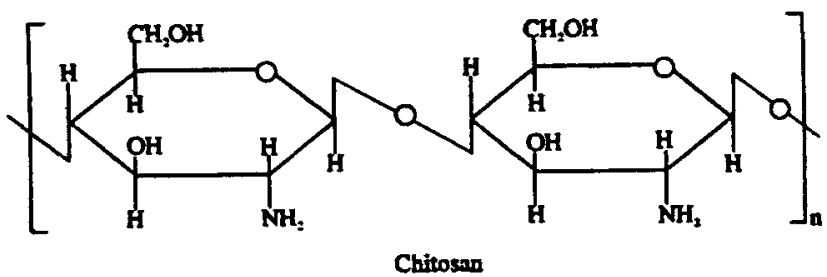

Figure 1. The structural relationship among cellulose, chitin and chitosan.

1.1a Economic aspects: The production of chitin and chitosan is currently based on crab and shrimp shells discarded by the canning industries in Oregon, Washington, Virginia and Japan and by various finishing fleets in the Antarctic. Several countries possess large unexploited crustacean resources e.g. Norway, Mexico and Chile (Muzzarelli et al 1987). The production of chitosan from crustacean shells obtained, as a food industry waste, is economically feasible, especially if it includes the recovery of carotenoids. The shells contain considerable quantities of astaxanthin, a carotenoid that has so far not been synthesized, and which is marketed as a fish food additive in aquaculture, especially for Salmon.

To produce $1 \mathrm{~kg}$ of $70 \%$ deacetylated chitosan from shrimp shells, $6.3 \mathrm{~kg}$ of $\mathrm{HCl}$ and $1.8 \mathrm{~kg}$ of $\mathrm{NaOH}$ are required in addition to nitrogen, process water $(0.5 \mathrm{t})$, cooling water $(0.9 \mathrm{t})$. Important items in estimating the production cost include transportation, which varies depending on labour and location. The worldwide price of chitosan is ca. US $\$ 7.5 / 10 \mathrm{~g}$.

In India, the Central Institute of Fisheries Technology, Kerala, initiated the research on chitin and chitosan. From their experiments, they found that dry prawn waste contained $23 \%$ and dry squilla contained $15 \%$ chitin (Madhavan and Nair 1978). In their further studies, they also reported that chitinous solid waste fraction of average Indian landing of shell fish ranged from 60,000 to 80,000 tonnes (Madhavan et al 1986). Chitin and chitosan are now produced commercially in India, Japan, Poland and Australia (Madhavan 1992).

\subsection{Properties of chitin and chitosan}

Most of the naturally occurring polysaccharides e.g. cellulose, dextran, pectin, alginic acid, agar, agarose, carragenans are neutral or acidic in nature, whereas chitin and chitosan are the examples of highly basic polysaccharides. Their unique properties include solubility behaviour, polyoxysalt formation, ability to form films, chelate metal ions and optical structural characteristics (Austin et al 1981).

Like cellulose, it naturally functions as a structural polysaccharide, but differs from cellulose in the properties (Muzzarelli 1978). Chitin is highly hydrophobic and is insoluble in water and most organic solvents. It is soluble in hexafluoroisopropanol, hexafluoroacetone (Capozza 1975), chloroalcohols in conjugation with aqueous solutions of mineral acids (Austin et al 1981) and dimethylacetamide containing 5\% lithium chloride (Rutherford and Austin 1978). Chitosan, the deacetylated product of chitin is soluble in very dilute acids like acetic acid, formic acid etc. Recently, gel forming ability of chitosan in $\mathrm{N}$-methyl morpholine- $\mathrm{N}$-oxide and its application in controlled drug release formulations has been reported (Dutta et al 1997; Dutta and Ravi Kumar 1997; Ravi Kumar et al 1999c, d, e). Hydrolysis of chitin with concentrated acids under drastic conditions produces relatively pure amino sugar, $\mathrm{D}$-glucosamine.

The nitrogen content in chitin varies from 5 to $8 \%$ depending on the extent of deacetylation, whereas, the nitrogen in chitosan is mostly in the form of primary aliphatic amino groups. Chitosan, therefore, undergoes the reactions typical to amines, of which $\mathrm{N}$-acylation and Schiff reaction are the most important. Chitosan derivatives are easily obtained under mild conditions and can be considered as substituted glucans.

$\mathrm{N}$-acylation with acid anhydrides or acyl halides introduces amido groups at the chitosan nitrogen. Acetic anhydride affords fully acetylated chitins. Linear aliphatic $\mathrm{N}$-acyl groups above proionyl, permit rapid acetylation of hydroxyl groups. High benzoylated chitin is soluble in benzyl alcohol, dimethyl sulfoxide, formic acid and dichloroacetic acid. The $\mathbf{N}$-hexanol, $\mathbf{N}$-decanoyl and $\mathbf{N}$ dodecanoyl derivatives have been obtained in methanesulfonic acid (Nishi et al 1979; Kaifu et al 1981).

At room temperature, chitosan forms aldimines and ketimines with aldehydes and ketones, respectively. Reaction with ketoacids followed by reduction with sodium borohydride produces glucans carrying proteic and non-proteic amino acid groups. $\mathrm{N}$-carboxy-methyl 
chitosan is obtained from glyoxylic acid. Examples of non-proteic amine acid glucans derived from chitosan are the $\mathrm{N}$-carboxybenzyl chitosans obtained from $o$ - and p-phthalaldehydic acids (Muzzarelli et al 1982a, b, 1983).

Chitosan and simple aldehydes produce $\mathrm{N}$-alkyl chitosan upon hydrogenation. The presence of the more or less bulky substituent weakens the hydrogen bonds of chitosan; therefore, $\mathrm{N}$-alkyl chitosan swell in water inspite of the hydrophobicity of alkyl chains. They retain the film forming property of chitosan (Muzzarelli 1977).

1.2a Physical and chemical characterization: The structural details of cellulose, chitin and chitosan are shown in figure 1. Cellulose is a homopolymer, while chitin and chitosan are heteropolymers. Neither random nor block orientation is meant to be implied for chitin and chitosan. The properties of chitin and chitosan like, origin of material (discussed in previous sections), crystalline form, degree of $\mathrm{N}$-deacetylation, molecular weight, solvents and solution properties have a major role to play in fibre formation.

1.2b Degree of $N$-acetylation: An important parameter to closely examine is the degree of $\mathrm{N}$-acetylation in chitin, i.e. the ratio of 2-acetamido-2-deoxy-D-glucopyranose to 2-amino-2-deoxy-D-glucopyranose structural units. This ratio has a striking effect on chitin solubility and solution properties. Chitosan, the universally accepted non-toxic $\mathrm{N}$-deacetylated derivative of chitin, where chitin is $\mathbf{N}$ deacetylated to such an extent, that it becomes soluble in dilute aqueous acetic and formic acids. To define this ratio, attempts have been made with IR spectroscopy (Sannan et al 1978; Maghami and Roberts 1988), pyrolysis gas chromatography (Lal and Hayes 1984), gel permeation chromatography and ultraviolet spectrophotometry (Aiba 1986), first derivative ultraviolet spectrophotometry (Muzzarelli and Rochetti 1985), circular dichroism measurements (Domard 1987), 'HNMR spectroscopy (Hirano et al 1981), ${ }^{13} \mathrm{C}$ solid state NMR (Pelletier et al 1990; Raymond et al 1993), thermal analysis (Alonso et al 1983), various titration schemes (Alonso et al 1983; Domszy and Roberts 1985; Raymond et al 1993), acid hydrolysis and HPLC (Niola et al 1993), separation spectrometry methods (Neugebauer et al 1989) and more recently, near-infrared spectroscopy (Rathke and Hudson 1993) and most of these methods have been thoroughly reviewed in literature (Muzzarelli and Rochetti 1985).

1.2c Molecular weight: Molecular weight is one of the important properties to be considered in all fibre studies. The weight average molecular weights $(\bar{M} w)$ of chitin and chitosan have been determined by light scattering (Muzzarelli et al 1987). Viscometry is a simple and rapid method for the determination of the molecular weight; the constants $a$ and $k$ in the Mark-Houwink equation have been determined in $0.1 \mathrm{M}$ acetic acid and $0.2 \mathrm{M}$ sodium chloride solution. The intrinsic viscosity is expressed as:

$$
[\eta]=K M^{\alpha}=1.81 \times 10^{-3} \mathrm{M}^{0.93} .
$$

To the charged nature of chitosan in acid solvents and chitosan's propensity to form aggregation complexes requires care when applying these constants. Furthermore, converting chitin into chitosan lowers the molecular weight, changes the degree of deacetylation, and thereby alters the charge distribution, which in turn influences the agglomeration. The weight-average molecular weight of chitin is $1.03^{6} \times 10^{6}$ to $2.5 \times 10^{6}$ daltons, but the $\mathrm{N}$-deacetylation reaction reduces this to $1 \times 10^{5}$ to $5 \times 10^{5}$ daltons (Roberts and Domszy 1982; Domard and Rinaudo 1983).

$1.2 \mathrm{~d}$ Solvent and solution properties: Both cellulose and chitin are highly crystalline, interactable materials and only a limited number of solvents are known, which are applicable as reaction solvents. Chitin and chitosan degrade before melting, which is typical for polysaccharides with extensive hydrogen bonding. This makes it necessary to dissolve chitin and chitosan in an appropriate solvent system to spin fibres. Residual solvent must then be either leached or evaporated out of the fibre.

Solution properties of chitin and chitosan have also been studied extensively. For fibre spinning, the objective is to obtain a homogeneous nongel solution with a maximum polymer-to-solvent ratio. For each solvent system, polymer concentration, $\mathrm{pH}$, counterion concentration, and temperature effects on the solution viscosity must be known. The comparative data from solvent to solvent are not available. As a general rule, researchers dissolve the maximum amount of polymer in a given solvent that still retained homogeneity and then spun fibres without further characterization of the solution. A coagulant is required for polymer regeneration or solidification, while casting fibres out of solutions. The nature of the coagulant is also highly dependent on the solvent and solution properties as well as the polymer used.

\subsection{Wet spinning}

The process of wet spinning has been reviewed by many researchers (Paul 1968; Moncreiff 1970; Ziabicki 1985). However, it is important to visualize the wet spinning process to understand chitin and chitosan fibre spinning. A schematic representation of wet spinning process is shown in figure 2 . Usually, the spin dope is inserted in a spin cylinder and is pushed downward by a piston to extrude a liquid jet through a spinneret. This can be accomplished continuously by screw extruder. The liquid jet may be immersed directly into a coagulation bath or it can also go through an inert gas gap first. The purpose of 


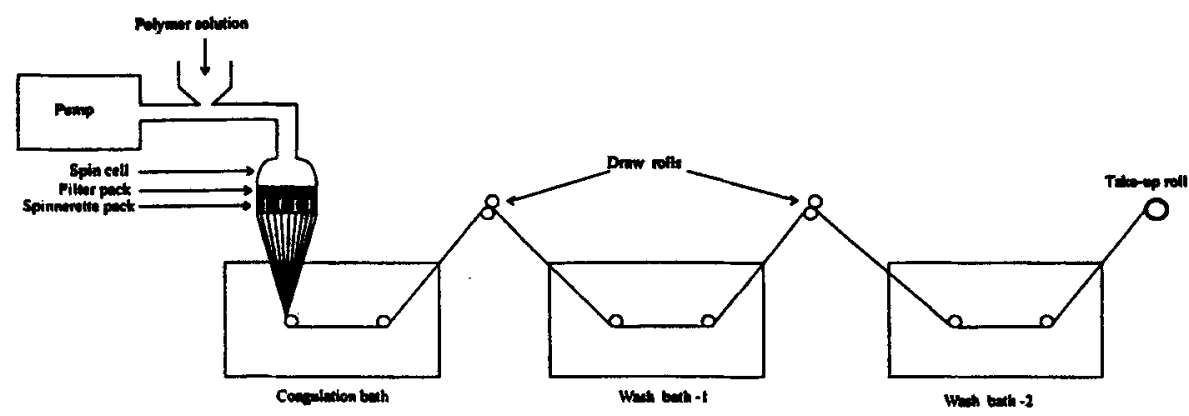

Figure 2. Schematic representation of wet spinning system.

gas gap and coagulation baths is to solidify the fibre by setting up a skin through which the solvent inside the fibre can diffuse. The first set of roller winds up the fibre and can give the initial draw. One or two additional baths can be used for solvent removal and washing. They can also be used to provide additional fibre drawing under wet conditions. The draw step does not have to occur to polymer chain alignment. Either or all baths can be necessary to remove residual solvent. While spinning fibres, the important need to be considered next to spinning solution composition are dimensions of the spinneret/coagulation bath and the draw ratio.

\section{Chitin and its derivatives in fibre formation}

\subsection{Natural microfibriller arrangement}

Chitin has been known to form microfibrillar arrangements in living organisms. These fibrils are usually embedded in a protein matrix and have diameters from 2.5 to $2.8 \mathrm{~nm}$. Crustacean cuticles possess chitin microfibrils with diameters as large as $25 \mathrm{~nm}$. The presence of microfibrils suggest that chitin has characteristics which make it a good candidate for fibre spinning. To spin chitin or chitosan fibres the raw polymer must be suitably redissolved after removal of extraneous material such as calcium carbonate and proteins, which encase the microfibrils.

\subsection{Fibre formation-in retrospection}

Numerous methods of spinning chitin fibres have been reported since Von Weimarn reported the first solutions of chitin that could be formed into a "ropy-plastic" state in 1926. He prepared the solution using inorganic salts capable of strong hydration (Weimarn 1926a, b), such as $\mathrm{LiCNS}, \mathrm{Ca}(\mathrm{CNS})_{2}, \mathrm{CaI}_{2}, \mathrm{CaBr}_{2}, \mathrm{CaCl}_{2}$ etc. After that, many solvent systems including organic or mixture of inorganic salts and organic solvents came into existence.

The problems in dissolving chitin have been pointed out as early as 1926 (Kunike 1926). To help in the dissolution of chitin, it was $\mathrm{N}$-deacetylated in $5 \%$ caustic at $60^{\circ} \mathrm{C}$ for 14 days. Another procedure for the $\mathrm{N}$ deacetylation was to place the chitin in an autoclave for $3 \mathrm{~h}$ at $180^{\circ} \mathrm{C}$ and $10 \mathrm{~atm}$ pressure. He also pointed out that 6 to $10 \%$ solids of $\mathrm{N}$-deacetylated chitin can be brought into acidic solutions at room temperature. Aqueous acetic acid was found to be suitable for this purpose.

After sending polymer solutions through filter presses to remove impurities, fibres were spun. Chemicals incompatible with chitin were suggested as coagulants. The resultant fibres were washed and dried under tension. The final product fibres had a round to heart-shaped cross-section with a tensile breaking load of $35 \mathrm{~kg} / \mathrm{mm}^{2}$ $(345 \mathrm{~Pa})$. The fibres possessed a dull luster similar to natural silk, leading to the suggestion that the $\mathrm{N}$ deacetylated chitin fibres would make good artificial hair. The collection and recycling of chitin from small-scale consumers was also suggested. Kunike made an early patent application on plastic masses of chitin on this procedure at the Kaiser-Wilhelm-Institut fuer Fasertoffchemie in 1926 (Kunike 1926).

Two scientists reported a procedure for producing fibres by dissolution of chitin at $95^{\circ} \mathrm{C}$ in presaturated solutions of lithium thiocyanate (saturated at $60^{\circ} \mathrm{C}$ ) (Clark and Smith 1936). No tensile properties or solution concentrations were reported. However, X-ray analysis showed a high degree of orientation. Solvent removal was not successful even at $200^{\circ} \mathrm{C}$. Lithium iodide was implied to have behaved in the same manner. A ratio of 5-mole lithium thiocyanate per mole anhydroglucose unit was found to exist. This is comparable to the cellulose-lithium thiocyanate compound. Cellulose solubility and the role of solvate/salt complexes have been reviewed in detail (Hudson and Cuculo 1980: Dawsey and McCormick 1990).

\subsection{Novel solvent spin systems}

2.3a Halogenated solvent spin system: In 1975 Austin suggested organic solvents containing acids (chloroethanol and sulphuric acid) for the direct dissolution of chitin. The 
precipitation of chitin in fibrillar form in water, methanol, or aqueous ammonium hydroxide was mentioned, but no fibre tensile data were presented (Austin 1975a, b).

In 1975 Brine and Austin suggested trichloroacetic acid (TCA) as a chitin solvent. Chitin was pulverized and 2 parts by weight were added to 87 parts by weight of a solvent mixture containing $40 \%$ TCA, $40 \%$ chloral hydrate (US Department of Justice, Drug Enforcement Agency, class IV controlled substance), and $20 \%$ methylene chloride over a period of 30-45 min. A filament was extruded from this solution using a hypodermic needle and acetone as the coagulant. The filament was then neutralized with potassium hydroxide $(\mathrm{KOH})$ in 2propanol followed by washing in deionized water. The filaments were then cold drawn. Two tensile breaks were taken at $60 \%$ relative humidity and room temperature. The first was from a filament with a cross-section of $0.08 \times 0.10 \mathrm{~mm}$, yielding a tensile strength of $72 \mathrm{~kg} / \mathrm{mm}^{2}$ $(710 \mathrm{~Pa})$ and a breaking elongation of $13 \%$. The second filament had a cross-section of $0.014 \times 0.740 \mathrm{~mm}$, indicating a collapsed core structure. It had a tensile strength of $104 \mathrm{~kg} / \mathrm{mm}^{2}(1026 \mathrm{~Pa})$ and a breaking elongation of 44\% (Brine and Austin 1975). Syringing a filament cannot be interpreted as conclusive evidence for a possible wet spinning process. While syringe extrusion might indicate the selection of a coagulant, rather it would be surprising to obtain meaningful tensile data. Shear forces in a spinneret are much greater than those experienced in a syringe tip.

Kifune and co-workers suggested dissolving chitin in TCA and a chlorinated hydrocarbon such as chloromethane, dichloromethane, and 1,1,2-trichloroethane. The TCA concentration should be kept between 2.5 and $75 \%$ by weight. A concentration range between 1 and $10 \%$ chitin was suggested as well as dissolution below room temperature. Fibres were extruded through a spinneret of diameter 0.04 and $0.06 \mathrm{~mm}$ into an acetone coagulation bath followed by a methanol bath. The tensile strength of dried filaments were in the range 1.67-3.1 g/d with an elongation from 8.7 to $20 \%$. The strength of the fibres was improved by leaving them in $0.5 \mathrm{~g} / \mathrm{L}$ aqueous caustic solution for $1 \mathrm{~h}$. The resultant tensile strengths were $2 \cdot 25$ $3.20 \mathrm{~g} / \mathrm{d}$ with elongations of $19.2-27.3 \%$, respectively (Kifune et al 1987). Kifune and co-workers further suggested that these chitin filaments were suitable as absorbable surgical sutures (Kifune et al 1990). However, TCA is very corrosive and degrades the polymer molecular weight. The breaking elongations suggest that the halogenated solvents act as plasticisers.

Fuji Spinning Company dissolved chitosan in a mixture of water and dichloroacetic acid (DCA). The 6.44\% chitosan acetate salt solution viscosity was 410 poise. The dope was extruded through a platinum nozzle ( 30 holes of $0.2 \mathrm{~mm}$ diameter each) into basic $\mathrm{CuCO}_{3}-\left(\mathrm{NH}_{4}\right) \mathrm{OH}$ solution to form fibres. Denier and tensile properties were not reported (Fuji Co. 1984).
Capozza (1975) suggested a combination of hexafluoroisopropanol and hexafluoroacetone sesquihydrate as a solvent system. Chitin was spun into fibres using this system. Dry spinning was accomplished by heating a solution containing chitin and 97 parts hexafluoroisopropanol to $55^{\circ} \mathrm{C}$ and extruding through a spinneret having 16 capillaries of $0.1 \mathrm{~mm}$ diameter. The fibres were autoclaved by steam but no tensile properties were given. Wet spinning was accomplished by extruding a 3\% solution of chitin in hexafluoroacetone sesquihydrate into an acetone coagulation bath. The solution was further washed with acetone and then dried and drawn. Comparative tensile strengths were not reported (Capozza $1976 \mathrm{a}, \mathrm{b} ; 1978 \mathrm{a}, \mathrm{b})$. Both solvents are highly toxic (hexafluoroisopropanol orl-mus $\mathrm{LD}_{50}=600 \mathrm{mg} / \mathrm{kg}$ ) which makes complete solvent recovery imperative.

Tokura et al (1979) used a combination of FA, DCA, and isopropylether as a solvent system. Chitin was cycled several times from $-20^{\circ} \mathrm{C}$ to room temperature in FA, followed by the addition of a small amount of DCA. Isopropylether was then added to reduce the solution viscosity to below 199 poise. Different coagulation systems were used as shown in table 1 . Table 2 shows the filament tensile properties (Tokura et al 1979). Dry tenacities were below $1.59 \mathrm{~g} / \mathrm{d}$ and no elongations above $4.3 \%$ were obtained. It is noteworthy that the wet strength drops to below $0.50 \mathrm{~g} / \mathrm{d}$ but that the elongation increases to as high as $13 \%$.

A TCA/dichloromethane spin system is also described by the Unitika Co., Ltd. Three parts chitin were dissolved in 50 parts TCA and 50 parts dichloromethane by weight. The defoamed dope was extruded into acetone before wind-up. The bobbins were neutralized with $\mathrm{KOH}$, washed with water, and dried. The fibres had a tensile strength of $2 \mathrm{~g} / \mathrm{d}$ and $0.5-20$ denier (Unitika Co. Ltd 1982a).

Unitika Co., also used the TCA-chloral hydrate dichloroethane solvent system for chitin. Five parts chitin were dissolved in 100 parts of a $4: 4: 2$ TCA : chloral hydrate : dichloroethane solvent mixture and extruded through a $0.06 \mathrm{~mm}$ nozzle into acetone. The fibres were treated with methanolic $\mathrm{NaOH}$. The optimum fibres gave tenacity of $3.2 \mathrm{~g} / \mathrm{d}$ with an elongation of $20 \%$ (Unitika Co. Ltd 1982b). Unitika Co. followed this up with another patent using a $60: 40 \mathrm{TCA}$ : trichloroethylene spin dope mixture. Tensile properties were unavailable (Unitika Co. Ltd 1982c). In 1983 Unitika Co. showed that a dope consisting of 3 parts chitin, 50 parts TCA, and 50 parts dichloromethane could be spun at a rate of $1.7 \mathrm{ml} / \mathrm{min}$ under $25 \mathrm{~kg} / \mathrm{cm}^{2}$ pressure into acetone to form filaments. The extrusion die had 50 holes of $0.07 \mathrm{~mm}$ diameter each. This indicates a jet velocity of $8.8 \mathrm{~m} / \mathrm{min}$ and a take-up of $5 \mathrm{~m} / \mathrm{min}$. The coagulation bath was maintained at $18^{\circ} \mathrm{C}$. The filaments were washed with acetone at $18^{\circ} \mathrm{C}$ for $10 \mathrm{~min}$ rewound at $4.5 \mathrm{~m} / \mathrm{min}$, then neutralized, washed and dried. The multifilament product had a total denier of 
150 with a tenacity of $2.65 \mathrm{~g} / \mathrm{d}$ (Unitika Co. Ltd 1983a). A similar system using 4 parts chitin in the same solvent but a 40-hole die of $0.08 \mathrm{~mm}$ diameter each was also used. The jet velocity was $10.4 \mathrm{~m} / \mathrm{min}$ into a $25^{\circ} \mathrm{C}$ acetone bath. A. rewinding at $7 \mathrm{~m} / \mathrm{min}$ followed the first takeup roll at $5 \mathrm{~m} / \mathrm{min}$. The total denier was 175 ; however, no tensile properties were reported (Unitika Co. Ltd 1983b).

Some of the halogenated solvent systems attained dry tenacities of above $3 \mathrm{~g} / \mathrm{d}$; however, the low wet tenacities were still undesirable. Although the fibre characterization was much better for these systems, the polymer characterization lacked molecular weight as well as degree of $\mathrm{N}$-acetylation formation. Solution properties would be hard to obtain due to rapid chitin degradation in these solvents. Although anhydrous coagulation baths were used and compared, fibres were neutralized in aqueous media. A study in completely anhydrous systems would be of interest, since it may lead to more densely consolidated fibres. The implementation of these spin systems represents a problem due to the nature of the solvents. TCA and DCA are corrosive and degrade the polymer upon short exposures. Chlorohydrocarbons are increasingly environmentally unacceptable solvents. Hexafluoroisopropanol and hexafluoroacetone sesquihydrate are toxic. Formic acid can act as a sensitizer.

Table 1. Spinning conditions for chitin fibres.

\begin{tabular}{|c|c|c|c|c|c|c|c|c|}
\hline & & & \multicolumn{6}{|c|}{ Sample number } \\
\hline & & & 31 & 56 & 79 & 80 & 61 & 62 \\
\hline \multirow[t]{2}{*}{ Spin condition: } & Solvent ${ }^{a}(v /$ & & $\begin{array}{l}\text { FA-DCA } \\
(92: 8)\end{array}$ & \multicolumn{3}{|c|}{$\begin{array}{l}\text { FA-DCA-iPE } \\
(83: 11: 5)\end{array}$} & \multicolumn{2}{|c|}{$\begin{array}{l}\text { FA-DCA-iPE } \\
(92: 5: 3)\end{array}$} \\
\hline & Conc. $(w / v)$ & & $3 \cdot 0$ & 4.0 & 3.8 & 3.8 & 4.6 & $4 \cdot 6$ \\
\hline Spinning pressure & \multicolumn{8}{|c|}{$1.0-1.3\left(\mathrm{~kg} / \mathrm{cm}^{2}\right)$} \\
\hline Nozzle & \multicolumn{8}{|c|}{ Platinum, $0.09 \mathrm{~mm} \phi, 50$ holes } \\
\hline \multirow[t]{2}{*}{ Coagulation bath: } & $\begin{array}{l}\text { 1st EtOAc } \\
(31)\end{array}$ & $\begin{array}{l}\text { iPE } \\
(56)\end{array}$ & $\begin{array}{l}\text { Ace } \\
\text { (79) }\end{array}$ & $\begin{array}{c}\text { Ace-iPE } \\
(\mathbf{8 0 )}\end{array}$ & & $\begin{array}{l}\text { Ac } \\
\text { 1) }\end{array}$ & \multicolumn{2}{|c|}{$\begin{array}{c}\text { EtOAc-iPE } \\
\quad(62)\end{array}$} \\
\hline & 2nd EtOH & $50 \% \mathrm{AcOH}$ & EtOH $(2: 5)$ & cold water & & & & \\
\hline $\begin{array}{l}\text { Stretching bath } \\
1 \text { st roller, } \mathrm{m} / \mathrm{min} \\
\text { 2nd roller, } \mathrm{m} / \mathrm{min} \\
\text { Elongation ratio }\end{array}$ & $\begin{array}{l}5.6 \\
7.3 \\
1.32\end{array}$ & $\begin{array}{l}5 \cdot 2 \\
5 \cdot 8 \\
1 \cdot 10\end{array}$ & $\begin{array}{c}\text { Water } 60^{\circ} \mathrm{C} \\
6.5 \\
7.8 \\
1.20\end{array}$ & & $\begin{array}{l}6.2 \\
8.0 \\
1.29\end{array}$ & & $\begin{array}{l}6.2 \\
8.4 \\
1.35\end{array}$ & \\
\hline
\end{tabular}

(Source: Tokura et al 1979)

Abbreviations: FA formic acid, DCA dichloroacetic acid, iPE isopropylalcohol, EtOAc ethylacetate, ACe acetone, $\mathrm{AcOh}$ acetic acid, cold water $12-14^{\circ} \mathrm{C}$

Table 2. Properties of chitin fibres.

\begin{tabular}{lcccccc}
\hline & \multicolumn{7}{c}{ Sample number } \\
\cline { 2 - 7 } & 31 & 56 & 61 & 62 & 79 & 80 \\
\hline Tenacity, g/d: & & & & & & \\
Dry $\left(20^{\circ} \mathrm{C}, 65 \%\right.$ R.H $)$ & 1.32 & 0.68 & 1.33 & 1.02 & 1.26 & 1.59 \\
Wet $\left(20^{\circ} \mathrm{C}, 65 \%\right.$ R.H) & 0.18 & 0.23 & 0.27 & 0.14 & 0.16 & 0.23 \\
Wet $\left(20^{\circ} \mathrm{C}, 100 \%\right.$ R.H) & 0.18 & 0.23 & 0.50 & 0.40 & 0.27 & 0.37 \\
Elongation \%: & & & & & & \\
Dry (20 C, 65\%R.H) & 2.7 & 2.9 & 4.3 & 2.8 & 3.4 & 2.7 \\
Wet $\left(20^{\circ} \mathrm{C}, 65 \%\right.$ R.H) & 7.8 & 10.8 & 8.6 & 4.6 & 4.6 & 3.6 \\
Wet $\left(20^{\circ} \mathrm{C}, 100 \%\right.$ R.H) & 7.1 & 13.0 & 10.1 & 8.8 & 6.8 & 7.5 \\
Knot strength, g/d & 0.45 & 0.45 & 0.24 & 0.11 & 0.12 & 0.08 \\
Density, g/cm & 1.382 & 1.347 & 1.385 & 1.384 & 1.395 & 1.397 \\
Moisture recovery\% & 12.9 & 13.0 & 14.1 & 14.7 & 12.9 & 14.0 \\
Denier, d & 25.5 & 3.2 & 2.1 & 2.0 & 2.0 & 3.0 \\
\hline
\end{tabular}

(Source: Tokura et al 1979) 
2.3b Amide-LiCl system: In 1978 Rutherford and Austin published Marine Chitin properties and Solvents. This summarized the problems encountered in finding a solvent system for chitin. Austin suggested N,N-dimethylacetamide (DMAc)-5\% LiCl or $\mathrm{N}$-methyl-2-pyrrolidone (NMP) $-5 \% \mathrm{LiCl}$ as solvents for chitin. A solution of 5\% $\mathrm{w} / \mathrm{v}$ was obtained within $2 \mathrm{~h}$ with these systems. A filament was extruded from the solution using a 15 gauge needle into an acetone coagulation bath. This was followed by more washing and drawing in acetone. The final filament was washed in deionized water. Tensile properties were obtained at $60 \% \mathrm{RH}$ and room temperature at an applied stress of $0.1 \mathrm{~cm} / \mathrm{min}$. The resultant dry tensile strengths for different crab and shrimp species ranged from 24 to $60 \mathrm{~kg} / \mathrm{mm}^{2}$ (236-592 Pa). Austin published another comprehensive paper in which he elaborated on chitin solvents but not fibres (Austin 1984).

Kifune et al (1984) also dissolved chitin in an amide$\mathrm{LiCl}$ solution. The solution was extruded through a $0.05 \mathrm{~mm}$ spinneret into a butylalcohol coagulant. The dry tensile strength of the fibres was $50 \mathrm{~kg} / \mathrm{mm}^{2}$ (493 Pa). Kifune et al $(1987,1990)$ also elaborated on this spin system. A spin dope concentration of 1 to 10\% in NMP of DMAc- $\mathrm{LiCl}$ is suggested with an alcohol coagulation bath followed by a draw bath and further washing.

Several other Japanese patents also used the DMAc$\mathrm{LiCl}$ spin system. Unitika $\mathrm{Co}$. claimed fibres spun from a solution containing $0.5 \mathrm{~g}$ chitin, $8 \mathrm{~g} \mathrm{LiCl}$, and $100 \mathrm{~g}$ DMF. The viscosity of the solution was 50-600 centipoise at $30^{\circ} \mathrm{C}$ depending on the chitin concentration. A $3 \%$ chitin dope in a 20:1 DMF: $\mathrm{LiCl}$ solvent was spun through a die of 50 holes of $0.08 \mathrm{~mm}$ diameter each into an isobutanol coagulation bath at $10 \mathrm{~m} / \mathrm{min}$. This gave 61 denier fibres with tenacities of $3.81 \mathrm{~g} / \mathrm{d}$ after washing and drying (Unitika Co. Ltd 1983c). This was followed by spinning a $3.5 \%$ chitin solution dissolved in a $25: 3$ NMP : $\mathrm{LiCl}$ solution into $70^{\circ} \mathrm{C}$ isobutanol. No tensile properties were reported. Unitika Co. (1984a) also reported a 58 denier filament with a tenacity of $4.25 \mathrm{~g} / \mathrm{d}$ by spinning a dope consisting of $11 \mathrm{~g}$ chitin and $200 \mathrm{~g}$ of $8 \% \mathrm{LiCl}$ in NMP solution. The coagulant was isobutanol. Along the same lines, a dope was prepared containing $3 \mathrm{~g}$ chitin and $200 \mathrm{~g}$ of saturated $\mathrm{LiCl}$ in dimethylacetamide solution. To this dope another $0.5 \mathrm{~g} \mathrm{LiCl}$ was added before spinning into isobutanol. The final 65 denier filament had a tenacity of $4.18 \mathrm{~g} / \mathrm{d}$ (Unitika Co. Ltd 1984b). It is unclear if this high denier was for fibres or multifilaments; in general, high denier fibres result in poor tensile properties.

A group of Russian researchers spun chitin fibres out of DMAc/NMP solutions containing $5 \%$ chitin and $5 \% \mathrm{LiCl}$ (based on chitin content). The fibres were drawn in a 50:50 ethanol: ethylene glycol bath, giving average yield strength of $390 \mathrm{MPa}$ with $3 \%$ elongation. An initial modulus of $2 \mathrm{GPa}$ was also reported. Scanning electron microscopy showed fibres with a round fibrillar cross- section (Sukhanova et al 1989). A follow-up study showed a decrease in the elasticity modulus and relative elongation with the increase in degree of $\mathrm{N}$-acetylation (12-30\%). From X-ray analysis, an increase in the amount of amorphous regions was observed with the increase in degree of acetylation (Nud'ga et al 1991).

The amide-lithium systems showed some of the best dry tenacities although they still lacked adequate wet tenacities. The low wet tenacities were probably due to low crystalline and poor consolidation of the fibre. The fibres and spin dopes were well characterized but the polymers used to prepare these dopes were not. Some coagulation studies were carried out but a clear comparison could not be made. A very real problem with this spin system is the removal and recovery of lithium from the fibre. The lithium acts as a Lewis acid by solvating the chitin amide group. It is unclear if this can be completely reversed through washing, once the fibres have formed.

2.3c Amine oxide/water system: Attempts have been made to develop a process for chitosan fibres by direct

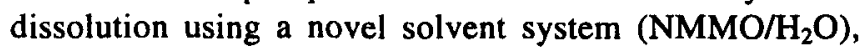
but no interesting tensile data were obtained from these preliminary investigations (Dutta and Ravi Kumar 1997).

\section{Applications of chitin and chitosan fibres}

\subsection{Chitin and chitosan-based dressings}

Chitin and chitosan have many distinctive biomedical properties and have been applied in many different industrial areas (Ravi Kumar et al 1999). However, chitin-based wound healing products are still at the early stage of research (Le et al 1997).

Sparkes and Murray (1986) developed a surgical dressing. This dressing is made of chitosan-gelatin complex. The procedure involves dissolving the chitosan in aqueous acetic acid, maintaining $\mathrm{pH}$ of the solution of about 2-3, followed by adding the gelatin dissolved in water. The weight ratio of chitosan and gelatin is $3: 1$ to $1: 3$. To reduce the stiffness of the resulting dressing a certain amount of plasticisers such as glycerol/sorbitol could be added to the mixture. Dressing film was cast from this solution on a flat plate and dried at room temperature. It was claimed that in contrast to the conventional biological dressings this experimental dressing displayed excellent adhesion to subcutaneous fat.

Nara et al (1987) patented a wound dressing comprising a nonwoven fabric composed of chitin fibres made by wet spinning technique. In one of the examples, chitin powder was ground to 100 mesh and treated in $1 \mathrm{~N} \mathrm{HCl}$ for $1 \mathrm{~h}$ at $4^{\circ} \mathrm{C}$. It was then heated to $90^{\circ} \mathrm{C}$ where it was treated for $3 \mathrm{~h}$ in a $3 \% \mathrm{NaOH}$ solution to remove calcium and protein in the chitin powder, and rinsed repeatedly 
followed by drying. The resultant chitin had a viscosity of $256 \mathrm{cP}$ at $30^{\circ} \mathrm{C}$ when it was dissolved in a dimethylacetamide solution containing $8 \mathrm{wt} \%$ lithium chloride to form a $0.2 \mathrm{wt} \%$ solution. The chitin was dissolved in a dimethylacetamide solution containing lithium chloride of $7 \mathrm{wt} \%$ to form a $7 \%$ dope. After filtering and holding to allow defoaming to occur, the dope was transformed to nozzle having a diameter of $0.06 \mathrm{~mm}$ and 200 holes from a charged tank under pressure by a gear pump and extruded into butanol at $60^{\circ} \mathrm{C}$ at the rate of $2.2 \mathrm{~g} / \mathrm{min}$. The chitin was coagulated and collected at the speed of $10 \mathrm{~m} / \mathrm{min}$. The resultant strand was rinsed with water and dried to obtain a filament of 0.74 dtex with strength of $2.8 \mathrm{~g} / \mathrm{den}$. The filaments were then cut into staple fibres. Nonwoven dressings were made by using polyvinyl alcohol as a fibrous binder.

In 1988 Kifune et al developed a new wound dressing, Beschitin W, composed of chitin nonwoven fabric and has been proved to be beneficial in clinical practice.

Kim and Min (1988) have developed a wound covering material from polyelectrolyte complexes of chitosan with sulfonated chitosan. It is proposed that wound healing is accelerated by the oligomers of degraded chitosan by tissue enzymes and this material was found to be effective in regenerating the skin tissue of wound area.

Biagini et al (1991) developed a chitosan derivative, $\mathrm{N}$ carboxybutyl chitosan derivative used in dressing for treating the plastic surgery donor sites. The solution of $\mathrm{N}$ carboxybutyl chitosan was dialyzed and freeze-dried to produce $10 \times 20 \times 0.5 \mathrm{~cm}^{3}$ soft and flexible pad, which was sterilized and applied to the wound. They reported that this dressing could promote ordered tissue regeneration compared to control donor sites, better histoarchitectural order, better vascularization and the absence of inflammatory cells were observed at the dermal level, whilst fewer aspects of proliferation of the malpighian layer were reported at the epidermal level (Biagini et al 1991).

Another research group at the British Textile Technology Group (BTTG) patented a procedure for making chitin based fibrous dressing (Sagar et al 1985, $1986,1987,1991)$. However, in their method the chitin/ chitosan fibres were not made by the traditional fibrespinning technique and the raw materials were not from shrimp shell but from microfungi instead. Their procedure can be summarized as follows: (a) Micro-fungal mycelia preparation from culture of Mucor mucedo growing in a nutrient solution, (b) culture washing and treatment with $\mathrm{NaOH}$ to remove protein and precipitate chitin/chitosan, (c) bleaching and further washing, (d) preparation of the dispersion of the fibres using paper-making equipment, and (e) filtration and wet-laid matt preparation; mixing with other fibres to give mechanical strength.

This is a novel method, which uses non-animal source as the raw material, and the resulting microfungal fibres are totally different from the normal spun fibres. Their structures seem to be irregular and highly branched. The fibres are unmanageably brittle when they are allowed to dry and a plasticiser has to be associated with the whole process and a wet-laid matt is the basic product.

Muzzarelli (1995) recently introduced another chitosan derivative, which was believed to be very promising in medical applications. This derivative is 5-methylpyrrolidinone chitosan, which was made by a series of chemical reactions. He claimed that this polymer is compatible with other polymer solutions including gelatin, poly(vinyl alcohol), poly(vinyl pyrrolidone) and hyaluronic acid. The advantages claimed by the inventor include healing of wounded mensical tissues, healing of decubitus ulcers, depression of capsule formation around prostheses, limitation of scar formation and retraction during healing. Some wound dressing samples were prepared in his work from the aqueous solution of this 5-methylpyrrolidinone chitosan, which was dialyzed and laminated between stainless steel plates and freeze-dried to yield fleeces. It is also claimed that this material could be fabricated into many different forms, such as filaments, nonwoven fabrics, etc. Once applied to a wound, 5-methylpyrrolidinone chitosan becomes immediately available in the form of oligomers produced under the action of lysozyme.

Another chitin derivative, dibutyrylchitin, was spun into fibre recently by a research group at the University of Leeds. Dibutyrylchitin was prepared by treatment of krill chitin with butyric anhydride in the presence of perchloric acid as a catalyst. The reaction was carried out at $25-30^{\circ} \mathrm{C}$. Samples of polymers with high molecular weights enough to form fibres were obtained, and dibutyrylchitin fibres were made by a simple method of dry spinning $20-22 \%$ solution in acetone. The results showed that the fibres had tensile properties similar to or better than those of chitin did and some chitin derivatives did. An attempt to convert dibutyrylchitin fibres to chitin fibres was made. It was claimed that chitin fibres with good tensile properties could be obtained by alkaline hydrolysis of dibutyrylchitin fibres without destroying the fibre structure (Szosland and East 1995). However, no information was given about the uses of this fibre.

As far as chitin-based commercial wound dressings are concerned, one product (Beschitin ${ }^{\otimes}$, Unitika) in Japan is commercially available, which is a nonwoven fabric manufactured from chitin filaments. At present, very few commercial dressings based on chitin or chitosan fibres are available in the market.

\subsection{Colour removal from textile mill effluents}

Colour, which contributes so much to the beauty of nature, is essential to the attractiveness and acceptability of most products used by modern society (Ravi Kumar and Dutta 1996). Textile wet processing operations produce high volumes of effluent wastewater of varied composition, often containing salts plus organic sur- 
factants, solvents and dyes. Since mid 1970s, colour pollution regulations have been 'on the books', but until recently have not been enforced. The textile industry's continuing concern for the environmental and desire to be better corporate citizens has brought reviewed emphasis on environmentally friendly products and production using technologies focusing on either source reduction (Dutta and Ravi Kumar 1998) or improved waste treatment (Ravi Kumar et al 1998b).

Much can still be done on both fronts and no single technique is likely to solve all problems, especially in the area of colour pollution control (Smith et al 1993). Mounting pressure on the textile industry to treat dye house effluents has led to a host of new and old technologies competing to provide cost-effective solutions. Among the oldest of methods for treatment of wastewater is the use of adsorbents derived from biological matter or biomass. Because of its low cost widespread availability, biomass has often been investigated with some promising results (Groff 1992, 1993; Cooper 1993; Reife 1993; Joseph 1994).

Experimental studies have demonstrated the possibility of using activated carbon particles, peat chitin and silica. All these adsorbents are of granular form. Since the adsorption capacities of the above adsorbents are not very large and the elution of the dyes is not easy, the viability of such a process depends on the development of an improved adsorbent.

Yoshida et al (1991) presented the equilibrium isotherms for the adsorption of dye anions (acid dye and direct dye) and dye cations (basic dye) on non-crosslinked chitosan fibres, and showed that at $\mathrm{pH} \cong 7$, the amounts of the dye anions absorbed on chitosan fibres were extremely large while the dye cations were not absorbed to any significant extent.

Chitosan is very stable in neutral and alkaline solutions, and can be safely used in solutions of $\mathrm{pH} \geq 7$. However, chitosan is soluble at low $\mathrm{pH}$, especially in organic acids, and this precludes the use of this material as an adsorbent under acidic conditions. To overcome this disadvantage and improve its acid and chemical stability, Yoshida et al (1993) again reported a novel method for preparation of crosslinked chitosan fibres and studied their adsorption behaviour on acid dyes. From their studies, they conclude that, the adsorption of acid dye on crosslinked chitosan fibres appeared to be technically and economically feasible.

\section{Conclusion}

From the foregoing sections it is clear that chitin and chitosan form unique position in materials family. Moreover, chitin and chitosan can readily be derivatized by utilizing the reactivity of the primary amino group and the primary and secondary hydroxyl groups to find applications in diversified areas. Although the primary scientific literature does not contain much fundamental information relating to fibres used for medication and especially for wound management, a large number of fibres have been used or developed for various applications. In addition, a significant number of patents disclose many novel techniques for the production of fibres for medical uses. In this review an attempt has been made to increase the understanding of the importance, characteristics and applications of chitin and chitosan fibres. It may take the dawn of 21 st century, when chitin and chitosan fibres will be commercially available in India, but a little effort is required from academic researchers as well as industrialists.

\section{References}

Aiba S 1986 Int. J. Biol. Macromol. 8173

Alonso I G, Peniche-Covas C and Neito J M 1983 J. Therm. Anal. 28189

Austin P R 1975a US Patent 3892731

Austin P R 1975b US Patent 3879377

Austin P R 1977 US Patent 4059457

Austin P R 1984 Chitin, chitosan and related enzymes (ed.) J P Zikakis (Florida: Academic Press) pp. 227-237

Austin P R and Brine C J 1977 US Patent 4029727

Austin P R, Brine C J, Castle J E and Zikakis J P 1981 Science 212749

Biagini Get al 1991 Biomaterials 12281

Brine C J and Austin P R 1975 in Amer. Chem. Soc. Symp. Series: Marine Chem. in Coastal Environ. (ed.) T D Church 18 pp. 505-518

Capozza R C 1975 German Patent 2505305

Capozza R C 1976a US Patent 3988411

Capozza R C 1976b US Patent 3989535

Capozza R C 1978a US Patent 4074366

Capozza R C 1978b US Patent 4074713

Chandy T and Sharma C P 1990 Biomater. Art. Cells Art. Org. 181

Clark G L and Smith A F 1936 J. Phys. Chem. 40863

Cooper P 1993 J. Soc. Dyer. Color 10997

Dawsey T R and McCormick C L 1990 J.M.S.-Rev. Macromol. Chem. Phys. C30 405

Domard A 1987 Int. J. Biol. Macromol. 9333

Domard A and Rinaudo M 1983 Int. J. Biol. Macromol. 549

Domszy J G and Roberts G A F 1985 Makromol. Chem. 186 1671

Dutta P K and Ravi Kumar M N V 1997 in Proc. Indian Chem. Convention (New Delhi: ICS)

Dutta P K and Ravi Kumar M N V 1998 Indian Patent $724 / \mathrm{Cal} / 98$

Dutta P K, Viswanathan P, Mimrot L and Ravi Kumar M N V 1997 J. Polym. Mater. 14351

Fuji Co. Ltd 1984 Japanese Patent 59116418; Chem. Abstr. 102 $12433 f$

Gessner S L 1992 US Patent 5108827; Chem. Abstr. 117 $71647 \mathrm{~m}$

Gorovoi L F, Baglai V A, Danilyak N I and Annikov O V 1990 Chem. Abstr. 11661872 w 
Groff K A 1992 Water Environ. Res. 64425

Groff K A 1993 Water Environ. Res. 65421

Hirano S, Tsuneyasu S and Kondo Y 1981 Agric. Biol. Chem. 451335

Hudson S M and Cuculo J A 1980 J.M.S.-Rev. Macromol. Chem. Phys. C18 1

Joseph Laszio A 1994 Am. Dyestuff Rep.

Kaifu K, Nishi N and Komai T $1981 \mathrm{~J}$. Polym. Sci. Polym. Chem. Ed. 192361

Kanayama N and Endo A 1991 Japanese Patent 03167388; Chem. Abstr. 155 235078p

Kifune K, Nakajima M and Atsumi K 1984 in Chitin, chitosan and related enzymes (ed.) J P Zikakis (New York: Harcourt Brace Janovich) pp. 407-410

Kifune K, Yamaguchi $Y$, Motosugi $K$, Nobe $Y$ and Tanae $H$ 1987a Japanese Patent 62097557; Chem. Abstr. 107 205230z

Kifune K, Yamaguchi $Y$ and Tanae H 1987b US Patent 4651725

Kifune K, Yamaguchi $Y$ and Motosugi K 1988 Japanese Patent 63209661; Chem. Abstr. 111 45347v

Kifune K, Yamaguchi Y and Kishimoto S 1988 Trans. Soc. Biomater. XI 216

Kifune K, Inome K and Mori S 1990 US Patent 4932404

Kim K Y and Min D S 1988 Trans. Soc. Biomater. XI 658

Kobayashi $\mathbf{Y}$, Nishiyama M, Matsuo R, Tokura S and Nishi N 1982 in Proc. of the second int. conf. on chitin and chitosan (eds) S Hirano and S Tokura (Tottori: The Japan Society of Chitin and Chitosan) pp. 239-243

Kunike G 1926 Chemiefasern 8126

Lal G S and Hayes E R 1984 J. Anal. Appl. Pyrol. 6183

Le Y, Anand S C and Horrocks A R 1997 Indian J. Fibre \& Textile Res. 22337

Madhavan P and Nair K G R 1978 in Proc. first int. conf. on chitin and chitosan (Cambridge: MIT) pp. 88-102

Madhavan P, Nair K G R, Thankappan T K, Prabhu P V and Gopakumar K 1986 Project Report (Kochi: CIFT)

Madhavan P 1992 in Popular Science Lecture Series (Kochi: CIFT)

Maghami G A and Roberts G A F 1988 Makromol. Chem. 189 2239

Moncreiff R W 1970 in Man-made fibres (New York: Wiley)

Mori $T$ and Yamazaki $T 1991$ Japanese Patent 03220394; Chem. Abstr. 116 59904q

Muzzarelli R A A 1973 in Naturally chelating polymers (New York: Pergamon) p. 83

Muzzarelli R A A 1977 in Chitin (New York: Pergamon) pp. 51-55

Muzzarelli R A A 1978 in Proc. first int. conf. on chitin and chitosan (Cambridge: MIT) pp. 1-3

Muzzarelli R A A 1993 Carbohydr. Res. 207

Muzzarelli R A A 1995 US Patent 537842

Muzzarelli R A A and Rochetti R 1985 Carbohydr. Res. 5461

Muzzarelli R A A, Tanfani F, Emanuelli $M J$ and Mariotti S 1982a Carbohydr. Res. 2145

Muzzarelli R A A, Tanfani F, Emanuelli $M J$ and Mariotti S 1982b Carbohydr. Res. 107199

Muzzarelli R A A, Tanfani F, Emanuelli M J and Mariotti S 1983 J. Membr. Sci. 16295

Muzzarelli R A A, Tanfani F and Scarpini G 1980 Biotechnol. Bioeng. 22885
Muzzarelli R A A, Lough C and Emanuelli M 1987 Carbohydr. Res. 164433

Nara K K, Yamaguchi Y and Tanae H 1987 US Patent 465I725

Neugebauer W A, Neugebauer E and Brezezinski R 1989 Carbohydr. Res. 189363

Niola F, Basora N, Chornet E and Vidal P F 1993 Carbohydr. Res. 2381

Nishi N, Noguchi J, Tokura S and Shiota H 1979 Polym. J. 1127

Nishiyama M, Kobayashi Y, Tokura S and Nishi N 1983 US Patent 4392916; Chem. Abstr. 16 124374p

Nud'ga L A et al 1991 Vysokomol. Soedin. Ser. B. 33864

Pariser E T and Lombadi D P 1980 in Chitin source book: A guide to research literature (New York: Wiley)

Paul D R 1968 J. Appl. Polym. Sci. 12383

Pelletier A, Lemire I, Sygush J, Chornet E and Overend R P 1990 Biotechnol. Bioeng. 36310

Rathke T D and Hudson S M 1993 J. Polym. Sci. Polym. Chem. Ed. 31749

Rathke T D and Hudson S M 1994 J.M.S.-Rev. Macromol. Chem. Phys. C34 375

Ravi Kumar M N V and Dutta P K 1996 Asian Textile J. 574

Ravi Kumar M N V, Rajakala Sridhari T, Durga Bhavani K and Dutta P K 1998a Colourage

Ravi Kumar M N V, Dutta P K and Nakamura S 1998b in Advances in wastewater treatment technologies (ed.) $\mathrm{R} K$ Trivedy (Aligarh: Global Science) pp. 22-46

Ravi Kumar M N V, Dutta P K and Nakamura S 1999a J. Sci. Ind. Res. (to be published)

Ravi Kumar M N V, Gupta K C, Dutta P K and Nakamura S 1999b Prog. Polym. Sci. (to be published)

Ravi Kumar M N V, Singh P and Dutta P K 1999c Indian Drugs (to be published)

Ravi Kumar M N V, Singh P and Dutta P K 1999d Eastern Pharm. (to be published)

Ravi Kumar M N V, Dutta P K and Nakamura S 1999e Indian J. Pharm. Sci. (to be published)

Raymond L, Morin F G and Marchessault R H 1993 Carbohydr. Res. 243331

Reife A 1993 in Encyclopedia of chemical technology (ed.) W Howe-Grant (New York: Wiley) pp. 753-783

Roberts G A F and Domszy J G 1982 Int. J. Biol. Macromol. 4374

Rutherford F and Austin P R 1978 in Proc. first int. conf. on chitin and chitosan (Cambridge: MIT) pp. 182-192

Sagar B, Hamlyn P and Waler D 1985 UK Patent 2148959

Sagar B, Hamlyn P and Waler D 1986 UK Patent 2165865

Sagar B, Hamlyn P and Waler D 1987 UK Patent 21888135

Sagar B, Hamlyn P and Waler D 1991 European Patent 460774; Chem. Abstr. 116914945

Salmon S and Hudson S M 1997 J.M.S.-Rev. Macromol. Chem. Phys. C37 199

Sannan T, Kurita K, Ogura K and Iwakura Y 1978 Polymer 19 458

Smith B, Koonce T and Hudson S 1993 Am. Dyestuff Rep.

Sparkes B G and Murray D G 1986 US Patent 4572906

Sukhanova T E, Sridorovich V, Goryainov G I, Mikhailov G M and Nitterpakhova 1989 Vysokomol. Soedin. Ser. B. 31381

Szosland B and East G C 1995 J. Appl. Polym. Sci. 58 2459

Taguchi T and Sato I 1989 Japanese Patent 03220394; Chem. Abstr. 111 156262h 
Tokura S, Nishi N and Noguchi J 1979 Polym. J. 11781

Unitika Co. Ltd 1982a European Patent 51421; Chem. Abstr. 97 $78943 \mathrm{~g}$

Unitika Co. Ltd 1982b Japan Patent 57139101; Chem. Abstr. 98 $55449 \mathrm{~g}$

Unitika Co. Ltd 1982c Japan Patent 57270717; Chem. Abstr. 98 $113745 p$

Unitika Co. Ltd 1983a Japan Patent 58214513; Chem. Abstr. $100180138 \mathrm{r}$

Unitika Co. Ltd 1983b Japan Patent 582145512; Chem. Abstr. 100 180139s

Unitika Co. Ltd 1983c Japan Patent 58127736; Chem. Abstr. $10087146 \mathrm{~g}$

Unitika Co. Ltd 1984a Japan Patent 59068347; Chem. Abstr. $101112325 v$
Unitika Co. Ltd 1984b Japan Patent 59071343, Chem. Abstr. $101112326 w$

Von Weimarn P P 1926a Can. Chem. Metall. 10227

Von Weimarn P P 1926b J. Textile Inst. 171642

Yamaguchi $\mathrm{H}$ et al 1987 Japanese Patent 62223399; Chem. Abstr. 108 44077h

Yao K D, Peng T, Yin J, Xu M and Goosen M F A 1995 J.M.S.Rev. Macromol. Chem. Phys. C35 155

Yoshida H, Fukuda S, Okamoto A and Kataoka T 1991 Water Sci. Technol. 231667

Yoshida H, Okamoto A and Kataoka T 1993 Chem. Eng. Sci. 482267

Ziabicki A 1985 in High-speed fibre spinning: Science and engineering aspects (New York: Wiley)

Zikakis J P (ed.) 1984 in Chitin, chitosan and related enzymes (Orlando: Academic Press) pp. XVII-XXIV 